\title{
Information and aggression in fishes
}

\author{
TOM M. PEAKE and PETER K. MCGREGOR \\ University of Copenhagen, Copenhagen, Denmark
}

\begin{abstract}
Aggressive interactions between fishes commonly take place in a social environment in which uninvolved individuals (bystanders) have an opportunity to gather information about interactants. Signals frequently used during such interactions are designed to transmit information about resource-holding power and/or intention. They are generally related to the level of escalation reached and the eventual outcome of a fight. We consider here the information available in signaling and nonsignaling aspects of aggressive interactions. We focus, in particular, on information available to bystanders. We summarize evidence that bystanders alter their behavior toward interactants on the basis of information acquired while bystanding, and we discuss the sources of information that may result in this change of behavior. In particular, we distinguish eavesdropping (i.e., extracting information from signaling interactions) as a subset of bystanding (i.e., extracting information from all available sources). We conclude that considerations of aggressive strategies should include potential costs and benefits resulting from wider social contexts in which aggression occurs.
\end{abstract}

Animals use information to direct their behavior and, thus, to adapt to an environment, even if the environment is constantly changing. Information about the environment is available in the behavior of conspecifics, and information gathered from others can influence both the acquisition and the use of behaviors in the future (Heyes \& Galef, 1996).

Our recent research has dealt with a specific subset of such information gathering: eavesdropping, which we define as the extraction of information from signaling interactions between others (McGregor \& Dabelsteen, 1996). Much of our work has focused on signal exchange between males in aggressive contexts. In this article, we show how our research can be integrated with other work on aggressive social interactions.

Aggressive interactions represent a significant proportion of social interactions and often take place in a social environment - that is, one containing conspecifics not directly involved. Thus, in addition to the potential resource benefits of winning an aggressive interaction (e.g., food, shelter, or mates; Huntingford \& Turner, 1987), aggressive encounters provide an opportunity for opponents to obtain an accurate estimate of each other's resource-holding potential. Such encounters may, however, be costly, particularly as contests escalate (see, e.g., Maan, Groothuis, \& Wittenberg, 2001; Neat, Taylor, \& Huntingford, 1998).

T.M.P was supported by the Zoological Institute, Copenhagen University, and P.K.M. was supported by Marie Curie Fellowship HPMCFCT-2002-01999 from the European Union and by Statens Naturvidenskablige Forskningsråd Grant 21-01-0482. We thank Ryan Earley, Luc-Alain Giraldeau, Karen Hollis, Ricardo Matos, Rui Oliveira, Ingo Schlupp, and Jeff Galef for comments that improved the manuscript. Correspondence concerning this article should be addressed to T. M. Peake, Department of Animal Behavior, Zoological Institute, University of Copenhagen, Tagensvej 16, DK 2200 Copenhagen N, Denmark (email: tmpeake@zi.ku.dk).
Although most research on assessment during aggressive encounters has focused on mutual assessment between opponents, because aggression occurs in a social environment individuals not directly involved in an aggressive interaction also have an opportunity to gather information about the quality of the interactants. Aggressive interactions are often associated with signals that, together with information available in the interactions themselves, could provide third parties with an accurate estimate of the resource-holding potential of the contestants. Because of the long-range nature of many signals (relative to the spacing between animals, McGregor \& Peake, 2000), the use of signals during interactions should considerably extend the social context within which aggression occurs.

Most research on aggression has focused on the response of interactants to the outcome of aggressive interactions and the effect of the outcome of an aggressive interaction on subsequent interactions. Here, we begin by briefly summarizing sources of information available to the observer of an aggressive interaction, including signals and nonsignaling behaviors. We go on to describe experiments showing that the future behavior of individuals can be affected by information acquired by bystanding, and we conclude by discussing these findings in relation to current issues in socially acquired information in general.

\section{Sources of Information on Aggression}

There are several sources of information in an observed aggressive interaction that can be of use to individuals, both at the time of the interaction and thereafter. In addition, some features of animals that provide such information may either become more apparent or appear only during interactions. In this section, we first consider information (such as apparent body size) that is available before aggression begins and indicate why such information may not be reliable. 
Aggressive interactions are often considered a means by which opponents can assess one another's strengths and, as such, should be designed to promote an exchange of information between the individuals involved (Hurd, 1997). Much information exchanged in this way, together with other features of aggressive interactions, constitutes information that is available to bystanders - that is, individuals that are present when an interaction between other individuals takes place. In the remainder of this section, we consider three sources of information available to bystanders: information in signals, information in nonsignaling aggressive behaviors, and information in the interaction itself.

Information available before fights begin. The outcome of aggressive encounters is frequently determined by intrinsic features of the individuals involved that may be assessed without the need to observe them interact. Body size is one of the most important factors in determining contest outcome in fights between fishes of many species (Huntingford \& Turner, 1987). Many studies have shown that the eventual winners and losers of fights between cichlids can be predicted by the size or weight of the contestants (Huntingford, Taylor, Sneddon, \& Neat, 2001). Differences of as little as $2 \%$ in weight can be enough to predict the winners of fights (Barlow, Rogers, \& Fraley, 1986), although in some species (e.g., Tilapia zilii) weight differences as large as $40 \%$ could not reliably predict the winners of fights (Neat, Huntingford, \& Beveridge, 1998).

In territorial species, territory holders win a majority of fights with intruding individuals (see, e.g., Bolyard \& Rowland, 2000; Turner, 1994). Thus, cues that provide information on the territorial status of an individual are often reliable predictors of the outcome of future contests on that individual's territory. Opponents may also differ in the estimated value of the resource being contested (e.g., territory or breeding opportunity), and this difference may influence the outcome of a fight (see, e.g., Keeley \& Grant, 1993). When two or more features are opposed, predicting the outcome may be more difficult. In pumpkinseed sunfish (Lepomis gibbosus), a difference in size can initially be overridden by a difference in resource value in the opposite direction. For example, small fish attack first when defending a highly valued resource against a larger opponent (Dugatkin \& Ohlsen, 1990). A large difference in resource value can even overcome a small difference in size (Dugatkin \& Biederman, 1991).

Recent prior experience can also have a strong effect on the outcome of contests (Dugatkin, 1997). In a wide variety of taxa, individuals that have recently won a contest have been shown to have an increased likelihood of winning the next (see Chase, Bartolomeo, \& Dugatkin, 1994). Similarly, losing individuals have been shown to experience a decreased likelihood of winning the next contest. Such loser effects have been found to be particularly strong, causing recent losers to lose subsequent contests to opponents much smaller than themselves (Beacham, 1988; Dugatkin, 1997).

Thus, even when differences can be observed directly before encounters (e.g., differences in size or territorial residence), other factors may influence fights to the extent that outcomes are not entirely predictable. For example, male blue gouramis (Trichogaster trichopterus) conditioned to expect a fight upon presentation of a conditioning stimulus deliver more bites and tailbeats and are more likely to win fights than are nonconditioned opponents (Hollis, 1984; Hollis, Dumas, Singh, \& Fackelman, 1995). Similarly, male Siamese fighting fish (Betta splendens) in which hyperaggressiveness was induced by preexposure to another male before a fight show a high degree of escalation early in the fight (Halperin, Giri, Elliot, \& Dunham, 1998). However, such preexposed males went on to lose a majority of fights with males that had not been preexposed to another male. Thus, measures of fighting performance available to bystanders are not necessarily accurate predictors of eventual outcome.

Information in signals used during aggression. Of all signal modalities used during aggression by fishes, visual signals have received the most attention, no doubt because of the relative ease of their quantification by human observers. Many visual signals seem to act to increase apparent body size [e.g., spreading of tails and fins during interactions (Huntingford \& Turner, 1987) and erection of gill covers in Siamese fighting fish (Simpson, 1968) and blue gourami (Hollis, 1999)] and are often initially associated with a rapid approach toward an opponent (Hollis, 1999). Color changes may also be associated with aggressive interactions. For example, territorial bluehead wrasse (Thalassoma bifasciatum) rapidly change body color from opalescent to green when chasing conspecifics from the territory (Dawkins \& Guildford, 1993). Rapid changes in eye color are similarly associated with aggression in some species (e.g., Pomacentrus jenkinsi; Rasa, 1969). In some cases, such color changes may be associated with particular fighting behaviors. In the cichlid Nannacara anomala, the appearance of vertical bars is associated with mouth wrestling, whereas medial line displays are associated with tail beating (mouth wrestling and tail beating are discussed below; see also Hurd, 1997). In some species, semipermanent color patterns are indicative of age or breeding status, and, thus, may provide information about the likelihood of aggression (Guthrie, 1986).

In a wide range of species, vocalizations are produced during aggressive encounters, mainly during interactions that take place once visual contact has been made (Ladich, 1997). In croaking gourami (Trichopsis vittata), males muted by surgery were much more likely to lose contests than untreated males of similar size (Ladich, Brittinger, \& Kratochvil, 1992). Furthermore, a number of parameters of sound production in this species correlate with fight outcomes, suggesting that interactants could use vocalizations to assess one another (Ladich, 1997). Vocalizations produced during interactions are of high amplitude despite the small distance $(1-5 \mathrm{~cm})$ between those involved (Ladich et al., 1992). Consequently, similar information might be available to bystanders.

In weakly electric species, electric organ discharges (EODs) are produced in an aggressive context. For exam- 
ple, brown ghost knife fish (Apteronotus leptorhynchus) emit chirps (brief EOD modulations) during aggressive encounters and chirp more when interacting directly than when interacting across a barrier (Dunlap \& Larkins-Ford, 2003). In Gymnotus carapo, biting attacks are associated with an increase in the pulse rate of EODs that inhibits attack by opponents (Black-Cleworth, 1970). Also, characteristics of the EOD pattern can predict dominance in $G$. carapo (Westby, 1975). Although EODs travel relatively short absolute distances (about 1 m; Hopkins, 1999), such distances may encompass several individuals (Westby, 1988), and information encoded in EODs could be available to bystanders.

Chemical cues may also facilitate information transfer between interactants. Three-spine stickleback (Gasterosteus aculeatus) males were able to discriminate between displaying and nondisplaying conspecific males on the basis of exposure to water from chambers containing such males (Waas \& Colgan, 1992), suggesting either a chemical component to aggressive display or that physical activity can be assessed by reception of chemical by-products (see the review by Wisenden \& Stacey, in press).

In some cases, assessment seems to involve behaviors that have a large directly physical component, although they are frequently considered to be displays. For example, in many fishes tail beating occurs during contests (see, e.g., Enquist \& Jakobsson, 1986; Simpson, 1968). In this behavior, fish orient themselves parallel to the opponent and rapidly move their caudal fins towards the opponent. Aside from the visual component of this behavior that is most obvious to human observers, the movement of the tail causes a wave of water pressure to be directed at the opponent's lateral line organ (Hollis, 1999). Tail beating may thus both provide size/weight information to opponents (Hurd, 1997) and directly injure them (Hollis, 1999). Although the physical component of tail beating is likely to be relatively short-range, the act of tail beating is easily observable and may provide information to bystanders.

Information in nonsignaling aggressive behaviors. Many aggressive interactions involve behaviors that are not generally considered signals but may still provide information to bystanders. In the simplest case, the proximity of one fish to another may be an indication of level of aggression. Contests usually begin with fish approaching one another rapidly; thus, speed of approach may provide information on the quality or motivation of those involved. Other movements, such as aggressive chasing and fleeing, can also provide information.

In many species, fights escalate into a circling phase. In sticklebacks, males chase one another rapidly in a tight circle, often for many minutes (Bakker \& Sevenster, 1983). Such circling, or roundaboutfighting, occurs most frequently between closely matched males and is associated with prolonged fights (Bakker \& Sevenster, 1983).

Other means by which fish may directly judge one another's fighting abilities include mouth wrestling, a phenomenon well documented in aggressive encounters in ci- chlids, in which opponents grapple using open mouths (Neat, Taylor, \& Huntingford, 1998). Further escalation may lead to mouth locking, in which interactants prevent respiratory movements by holding one another's lips with closed mouths (Huntingford et al., 2001). In T. zilii, losing males tend to break free from the mouth-lock first (Neat, Huntingford, \& Beveridge, 1998). Although bystanders cannot gain as accurate information on fighting strength from mouth wrestling and mouth locking as opponents can, the duration of these kinds of agonistic behaviors may provide information on the relative strength of the combatants. Such information would be significantly enhanced if bystanders had some direct experience of the fighting ability of one of the observed combatants.

High levels of escalation involve a greater level of direct physical contact that has little or no signaling component. However, the extent and frequency of physical contact can predict eventual outcome and can be observed by bystanders. The most obvious cases of such physical contact are those that involve in directly aggressive attempts to cause injury by biting, use of spines to cause damage (see, e.g., Rasa, 1969), and aggressive chasing. In T. zilii, smaller winners showed significantly higher rates of biting than did losers (Neat, Huntingford, \& Beveridge, 1998), whereas losing male swordtails (Xiphophorus helleri) showed higher levels of biting before and after escalation than winning male conspecifics (Ribowski \& Franck, 1993).

Information in interactions. Probably the most basic information available to bystanders from observing an interaction is the fact that an aggressive act is taking place. Cichlid fish that witness fights between conspecifics show elevated hormone levels, suggesting a direct physiological link between simply witnessing aggression and subsequent behavior (Oliveira, Lopes, Carneiro, \& Canario, 2001). Individuals engaged in an aggressive interaction are also less able to perform behaviors that prevent actions by bystanders. For example, while fighting, interactants may be paying less attention to defense of mates or other resources (e.g., Creighton, 2001). Thus, knowledge that a particular individual is involved in a fight may allow bystanders to take advantage of that individual's resources in the short term. Furthermore, observing an individual defend resources may provide information about both its resources and its motivation and ability to defend them. The level of aggression that a particular interaction reaches may also provide information to bystanders. In many species, aggressive encounters consist of readily recognizable phases that increase in aggressiveness and cost as a fight progresses (Archer, 1988). Fights generally begin with low-cost displays that appear to facilitate transfer of size-related information such that encounters between males of very different sizes rarely progress further (Enquist \& Jakobsson, 1986). In brief interactions, the information content of the interaction itself may be small, but the fact that an interaction did not escalate may be revealing. When quality or motivation is closely matched, interactions may be prolonged or more likely to escalate to 
progressively more costly behaviors. Thus, the level of escalation reached may provide accurate information about those involved.

The relative performance of individuals is judged more effectively by examining interactions. Information that $\mathrm{A}$ outperforms B (which is made available by paying attention only to the absolute performance of each male) is both more relevant if the observer knows that $\mathrm{A}$ and $\mathrm{B}$ were in direct competition and more easily gained due to the close proximity of the opponents during interactions. In addition to such directly comparative information (e.g., A outperforms B), we consider relative performance information to include information on the relationship between the two opponents (e.g., A is dominant over B). Such relational information is, again, more easily gained if the observer is aware that $\mathrm{A}$ and $\mathrm{B}$ are interacting - that is, that observed behaviors performed by $\mathrm{A}$ are directed at $B$ and vice versa.

Finally, the outcome of an interaction provides information. In fact, interaction outcome is the source of information that has been considered most commonly in models that address communication during aggressive interactions (e.g., Chase, 1985; Johnstone, 2001). In addition to revealing the winner and loser, the outcome of an interaction includes other information, not least of which is the fact that the interaction is now over. If an interaction was prolonged or escalated, then observers may potentially infer that energy levels have been significantly depleted or directly observe that injuries were sustained. Thus, the outcome also includes the cost paid to reach that outcome (Hurd, 1997).

Communication occurring during aggressive interactions has been the focus of a great deal of theoretical attention (see, e.g., Enquist, 1985; Enquist \& Leimar, 1983; Maynard Smith, 1982). Formal models describe both the way in which individuals should respond to opponents on the basis of communication that occurs within an interaction and the extent to which animals should reveal their intentions during fights, but they rarely consider the implications of the social context within which such interactions occur. For example, many models predict that reliable information on the fighting ability of interactants should be withheld until late in a contest (see, e.g., Enquist, Leimar, Ljungberg, Mallner, \& Segardahl, 1990; Maynard Smith, 1982). However, in many laboratory studies, predictors of eventual winners and losers have been shown to occur at early stages of interactions.

Maan et al. (2001) suggest three possible reasons for this apparent paradox: (1) the costs of display may have initially been overestimated, (2) limited social experience means that individuals are less able to reliably evaluate such predictors, and (3) laboratory-staged interactions are unnatural and generally used particularly low levels of asymmetry. Maan et al. highlight one aspect of laboratory studies that may force fights to a higher level than would occur naturally: Losers are unable to escape due to the confined space in which such interactions occur, and, thus, are given little choice but to continue an aggressive interaction (the desperado effect; Grafen, 1987). Consideration of the social environment introduces a further possibility that could be termed the good loser hypothesis. Although losing quickly may reduce the direct costs of losing, being observed to lose quickly may adversely affect the outcomes of future encounters with other individuals. Consequently, the benefit of fighting and losing may have been underestimated by many models. Support for this idea comes from a study of green swordtails (Earley \& Dugatkin, 2002) in which losing males that escalated their degree of aggressiveness were less likely than those that had not escalated to receive aggression from, and lose contests to, males that had seen the interaction in which the losers had engaged.

\section{Evidence That Bystanders Acquire Information on Aggression}

There are several studies that show that bystanders acquire information by being present at but not involved in aggressive interactions (Dugatkin, 2001). Male Siamese fighting fish spent significantly more time close to, and apparently looking into, a compartment containing two male fish aggressively interacting across a transparent partition than one containing two male fish separated by an opaque partition and, therefore, not interacting aggressively (Oliveira, McGregor, \& Latruffe, 1998). This result suggests that aggressive interactions hold interest for males. The same study also showed that males allowed to see an aggressive interaction responded differently to interactants when they were subsequently allowed to interact with them individually. Specifically, males responded to individuals that they had seen lose by approaching and displaying sooner than to males that they had seen win (Oliveira et al., 1998). In these experiments, male subjects could see interactions but could not themselves be seen, because they were behind one-way glass.

Similar experiments with green swordtails have yielded similar results. Males allowed to see aggressive interactions between other males without themselves being seen were less willing to initiate contests with winners than with losers (Earley \& Dugatkin, 2002, in press). Also, males that had seen aggressive interactions were less willing to escalate contests than were males that had not seen contests.

Experiments with female fighting fish as subjects found that females first visited males they had seen win an aggressive interaction. Females visited such males more often and spent more time near and displaying to them than to males they had seen lose (Doutrelant \& McGregor, 2000). Once again, the subjects were behind one-way glass and could see the interactions but could not themselves be seen.

Juvenile rainbow trout (Onchorhynchusmykiss) that were allowed to interact with conspecifics that they had seen to be dominant in a previous encounter changed their aggression more rapidly than when interacting with fish that had been dominant but had not been seen by the subjects 
(Johnsson \& Åkerman, 1998). Again, the results suggest that information obtained while bystanding enabled individuals to make decisions about how to respond.

\section{Eavesdropping}

The examples discussed in the previous section show that bystanders can gather information from aggressive interactions. The information gathered could have come from various sources, such as nonsignaling behaviors produced during the fight or intrinsic differences in the individuals that have acquired extra saliency through involvement in a fight.

There has been considerable interest in whether animals are capable of using information that is present solely in the interaction (see, e.g., McGregor \& Peake, 2000; Peake, in press; Pepperberg, in press). This interest is reflected by the use of the term eavesdropping, which has been defined as extracting information from signaling interactions between others (McGregor \& Dabelsteen, 1996). Eavesdropping (or, more specifically, social eavesdropping; see Peake, in press) is a behavior demonstrated by a subset of bystanders that extract information from the exchange of signals during an interaction.

The key feature of social eavesdropping is that information is gained from observing an interaction. Therefore, attempts to demonstrate social eavesdropping have concentrated on ensuring that information likely to elicit a difference in response is contained only in the interaction observed. In songbirds, this has been achieved by providing subjects with the opportunity to eavesdrop on an interaction simulated by playback from two loudspeakers, each linked to a laptop computer. This allows potentially confounding variables, such as amount of song, to be kept constant and the difference in stimuli perceived by an eavesdropper, such as which loudspeakerplays songs overlapping those played by the other, to be a feature of the interaction (e.g., Naguib, Fichtel, \& Todt, 1999; Peake, Terry, McGregor, \& Dabelsteen, 2001, 2002; see also Peake, in press). It is possible that playback could similarly be used to restrict information to interactions in order to study eavesdropping in fish that communicate acoustically or electrically.

It is more difficult to exercise similar control when studying visual signaling interactions in fish, although in principle it could be achieved through the use of models or video playback (see, e.g., Oliveira et al., 2000). To our knowledge, there have been no such experiments with fish. Instead, two other approaches have been used in attempts to demonstrate that fish eavesdrop on visual interactions.

The first approach has been to control the most likely alternative sources of information that might elicit such changes in behavior from subjects. Oliveira et al. (1998) considered that the changes that occur in interacting fish (e.g., winner and loser effects; Dugatkin, 1997) might provide information about the outcome of interactions rather than (or as well as) information about the dynamics of the interaction. Oliveira et al. (1998) therefore conducted experiments that involved two interactions between similarly sized males displaying across a transparent barrier but that allowed subjects the opportunity to see only one of the interactions. The other interaction served as a control. The staged interactions were allowed to proceed for $15 \mathrm{~min}$, enough time for a difference in display activities of winners and losers to be detected by subjects, but too little time for losing males to adopt submissive coloration. Each of the four interacting males (two seen and two unseen) was then introduced, one at a time, into a male subject's compartment, and the subject's response to the intruder was measured. The subjects responded to individuals that they had seen lose by approaching and displaying sooner than to males that they had seen win. No such differences were seen in response to the unseen males, even though they too had won or lost contests. Similar controls were used by Doutrelant and McGregor (2000) and Earley and Dugatkin (2002), but not by Johnsson and Åkerman (1998). Like Oliveira et al. (1998), all found differences in response to seen and unseen contestants consistent with eavesdropping.

The second approach used to establish that information contained in the interaction (rather than other sources of information) directs future aggressive behavior has been to create a mismatch between the experience of interacting fish and the experience of the subject. McGregor, Peake, \& Lampe (2001) attempted to do this by separating interacting fish by means of a small compartment into which the subject could not see. In one treatment (the real interaction), the compartment was simply filled with water, which allowed the males to interact across the gap between them. In the other treatment (the apparent interaction), the compartment contained two male fish separated by an opaque partition, allowing each of the males seen by the subject to interact with a fish that could not be seen by the subject. From the subject's point of view, the two visible fish interacted directly with one another (as in the real interaction), when, in fact, each interacted with a fish that was not visible to the subject. Thus, in the apparent interaction, the subject's interpretation of the aggressive signals given by each visible male was decoupled from that male's actual experience in its own interaction with a hidden fish. In this situation, it would be possible for the subject to consider that a male had won the apparent interaction, whereas the male could actually have lost its interaction with the hidden fish (or vice versa). The results showed that subjects responded differently to the apparent winners and losers of interactions, strongly suggesting that information was extracted from features of the interaction rather than from any other source. Both approaches have produced results consistent with the hypothesis that fish eavesdrop. However, an unequivocal demonstration will require simulated interactions similar to those used with songbirds (Peake, in press).

\section{Conclusions}

Here, we have considered aggressive interactions between males only as sources of information. Many other types of interaction occur regularly within a social envi- 
ronment and provide similar levels of information to bystanders. Females have been shown to mate preferentially with males that have been observed to attract other females successfully (see, e.g., Dugatkin, 1992; Galef \& White, 1998; Schlupp \& Ryan, 1997; Westneat, Walters, McCarthy, Hatch, \& Hein, 2000). Similarly, females have been shown to reject males that have been rejected as mates by others (see, e.g., Witte \& Ueding, 2003). Mate preferences that are influenced by such socially acquired information may persist over time (White \& Galef, 2000b; Witte \& Massmann, 2003) and preferences may be generalized by females to males exhibiting similar characteristics to those seen to mate (White \& Galef, 2000a; Witte \& Noltemeier, 2002). Thus, information available in interactions between males and females may well facilitate such behavior. In some cases, interactions between fish of different species may also provide information-for example in the choice of cleaner wrasse (Labroides dimidiatus) by client fishes (see, e.g., Bshary, 2002).

In this article, we have reviewed the potential sources of information available to individuals that observe or otherwise detect aggressive interactions between conspecifics. We have presented evidence that such bystanding individuals are capable of extracting some of this information and using it in future encounters with previously observed interactants. We have said very little about the adaptive value of such behavior or about the effect that such behavior may have on the evolution of aggressive and/or signaling strategies. Although it may be intuitively obvious that individuals that have a more accurate assessment of the quality of opponents will have an advantage over those that do not, there is little empirical data available to support this notion. Some support comes from a study showing that territorial male red-capped cardinals (Paroaria gularis) are more likely to detect an intruder if it was previously detected by a neighboring male (Eason \& Stamps, 1993).

The arguments presented here demonstrate the value of considering the social context of sources of information in aggressive and other behaviors. This approach is rather different from that taken by game-theoretical models of aggression that focus on outcome. Our experience of considering communication within a wider social context (i.e., communication networks-see, e.g., McGregor \& Peake, 2000) has convinced us that models of communication need to reflect the costs and benefits of signals as an integral part of an aggressive strategy. Whether signals themselves are apparently free of cost (i.e., conventional or strategic) or costly (i.e., handicap- or performancerelated) is only part of the equation determining the cost of signal use in a wider social context. Similar arguments can be made for cost-benefit equations of nonsignaling components of aggressive interactions in relation to bystanding. In addition, the current theoretical framework does not enable us to make predictions about when, where, and how the extraction of information by bystanders is favored, or to predict the nature of the effects of such bystanders on the use of particular aggressive strategies.
However, a game-theoretical model that includes the strategy of eavesdropping (in which individuals base their choice of "hawk" or "dove" role on the outcome of the current opponent's previous fight) shows that eavesdroppers can affect the overall level of aggression in a population (Johnstone, 2001). Thus, in our understanding of the role of social information in the evolution of communication and aggression we are far behind, for example, the current level of understanding of social influences on foraging strategies (comprehensively reviewed by Galef \& Giraldeau, 2001). However, the rate at which support for and interest in the role of social information in the evolution of communication and aggression is growing suggests that a promising future lies ahead.

\section{REFERENCES}

ArCher, J. (1988). The behavioural biology of aggression. Cambridge: Cambridge University Press.

BAKKer, T. C. M., \& SeVEnster, P. (1983). Determinants of dominance in male sticklebacks (Gasterosteus aculeatus L.). Behaviour, 86, 5571.

Barlow, G. W., Rogers, W., \& Fraley, N. (1986). Do Midas cichlids win through prowess or daring? It depends. Behavioural Ecology \& Sociobiology, 19, 1-19.

BEACHAM, J. L. (1988). The relative importance of body size and aggressive experience as determinants of dominance in pumpkinseed sunfish Lepomis gibbosus. Animal Behaviour, 36, 621-623.

BLACK-CLEWORTH,P. (1970). The role of electric discharges in the nonreproductive social behaviour of Gymnotus carapo. Animal Behaviour Monographs, 3, 1-77.

Bolyard, K. J., \& Rowland, W. J. (2000). The effects of special context and social experience on the territorial aggression of male threespine stickleback. Behaviour, 137, 845-864.

BSHARY, R. (2002). Biting cleaner fish use altruism to deceive image scoring clients. Proceedings of the Royal Society of London: Series B, 269, 2087-2093.

CHASE, I. D. (1985). The sequential analysis of aggressive acts during hierarchy formation: An application of the "jigsaw puzzle" approach. Animal Behaviour, 33, 86-100.

Chase, I. D., Bartolomeo, C. \& Dugatkin, L. A. (1994). Aggressive interactions and inter-contest interval: How long do winners keep winning? Animal Behaviour, 48, 393-400.

Creighton, E. (2001). Mate guarding versus territorial defence in the common blackbird. Ibis, 143, 322-326.

DAwkins, M. S., \& GuILDFORD, T. (1993). Colour and pattern in relation to sexual and aggressive behaviour in the bluehead wrasse Thalassoma bifasciatum. Behavioural Processes, 30, 245-252.

Doutrelant, C., \& MCGREGOR, P. K. (2000). Eavesdropping and mate choice in female fighting fish. Behaviour, 137, 1655-1669.

DugatKIn, L. A. (1992). Sexual selection and imitation: Females copy the mate choice of others. American Naturalist, 139, 1384-1389.

DUGATKIN, L. A. (1997). Winner effects, loser effects and the structure of dominance hierarchies. Behavioral Ecology, 8, 583-587.

DUGATKIN, L. A. (2001). Bystander effects and the structure of dominance hierarchies. Behavioral Ecology, 12, 348-352.

DugATKIn, L. A., \& Biederman, L. (1991). Balancing asymmetries in resource holding power in pumpkinseed sunfish. Animal Behaviour, 42, 691-692.

Dugatkin, L. A., \& Ohlsen, S. (1990). Contrasting asymmetries in value expectation and resource holding power: Effects on attack behaviour and dominance in the pumpkinseed sunfish Lepomis gibbosus. Animal Behaviour, 39, 802-804.

DUNLAP, K. D., \& LARKINS-FoRD, J. (2003). Production of aggressive electrocommunication signals to progressively realistic social stimuli in male Apteronotus leptorhynchus. Ethology, 109, 243-258.

EARley, R. L., \& DugatKin, L. A. (2002). Eavesdropping on visual 
cues in green swordtail (Xiphophorus helleri) fights: A case for networking. Proceedings of the Royal Society of London: Series B, 269, 943-952.

EARley, R. L., \& DUgatKin, L. A. (in press). Fighting, mating and networking: Pillars of poeciliid sociality. In P. K. McGregor (Ed.), Ani mal communication networks. Cambridge: Cambridge University Press.

EASON, P. K., \& StAmPs, J. A. (1993). An early warning system for detecting intruders in a territorial animal. Animal Behaviour, 46, 1105 1109 .

ENQUIST, M. (1985). Communication during aggressive interactions with particular reference to variation in choice of behaviour. Animal Behaviour, 33, 1152-1161.

ENQUiST, M., \& JAKOBSSON, S. (1986). Decision making and assessment in the fighting behaviour of Nannacara anomala (Cichlidae, Pisces) Ethology, 72, 143-153.

ENQUIST, M., \& LEIMAR, O. (1983). Evolution of fighting behaviour: Decision rules and assessment of relative strength. Journal of Theoretical Biology, 102, 387-410.

Enguist, M., Leimar, O., Ljungberg, T., Mallner, Y., \& SegarDAHL, N. (1990). A test of the sequential assessment game: Fighting in the cichlid fish, Nannacara anomala. Animal Behaviour, 40, 1-15.

GAlEF, B. G., JR., \& GirAldEAU, L.-A. (2001). Social influences on foraging in vertebrates: Causal mechanisms and adaptive functions. Animal Behaviour, 61, 3-15.

GALEF, B. G., JR., \& White, D. J. (1998). Mate-choice copying in Japanese quail, Coturnix coturnix japonica. Animal Behaviour, 55, 545552.

GRAFEN, A. (1987). The logic of divisively asymmetric contests: Respect for ownership and the desperado effect. Animal Behaviour, 35, 462-467.

Guthrie, D. M. (1986). Role of vision in fish behaviour. In T. J. Pitcher (Ed.), The behaviour of teleost fishes. London: Croom Helm.

HAlPerin, J. R. P., Giri, T., Elliot, J., \& Dunham, D. W. (1998). Consequences of hyper-aggressiveness in Siamese fighting fish: Cheaters seldom prospered. Animal Behaviour, 55, 87-96.

Heyes, C. M., \& Galef, B. G., JR. (1996). Social learning in animals London: Academic Press.

HoLLIS, K. L. (1984). The biological function of Pavlovian conditioning: The best defense is a good offense. Journal of Experimental Psychology, 10, 413-425.

HoLLIS, K. L. (1999). The role of learning in the aggressive and reproductive behaviour of blue gouramis, Trichogaster trichopterus. Ex perimental Biology of Fishes, 54, 355-369.

Hollis, K. L., Dumas, M. J., Singh, P., \& Fackelman, P. (1995) Pavlovian conditioning of aggressive behavior in blue gourami fish (Trichogaster trichopterus): Winners become winners and losers stay losers. Journal of Comparative Psychology, 109, 123-133.

Hopkins, C. D. (1999). Design features for electric communication. Journal of Experimental Biology, 202, 1217-1228.

Huntingford, F. A., TAYlor, A. C., Sneddon, L. U., \& Neat, F. C. (2001). Prowess and the resolution of animal fights. In Y. Espmark, T. Amundsen, \& G. Rosenqvist (Eds.), Animal signals: Signalling and signal design in animal communication (pp. 259-276). Trondheim: Tapir Academic Press.

Huntingford, F. A., \& TuRner, A. K. (1987). Animal conflict. London: Chapman \& Hall.

HURD, P. L. (1997). Cooperative signalling between opponents in fish fights. Animal Behaviour, 54, 1309-1315.

JoHnSSON, J. I., \& A KERMAN, A. (1998). Watch and learn: Preview of the fighting ability of opponents alters contest behaviour in rainbow trout Animal Behaviour, 56, 771-776.

Johnstone, R. A. (2001). Eavesdropping and animal conflict. Proceedings of the National Academy of Sciences, 98, 9177-9180.

KeELEY, E. R., \& GRANT, J. W. A. (1993). Visual information, resource value, and sequential assessment in convict cichlid (Cichlasoma nigrofasciatum) contests. Behavioral Ecology, 4, 345-349.

LADICH, F. (1997). Agonistic behaviour and significance of sounds on vocalising fish. Marine \& Freshwater Behaviour \& Physiology, 29, 87-108.

LAdich, F., Brittinger, W., \& KratochVil, H. (1992). Significance of agonistic vocalization in the croaking gourami (Trichopsis vittatus, Telostei). Ethology, 90, 307-314.

MaAn, M. E., Groothuis, T. G. G., \& WittenberG, J. (2001). Escalated fighting despite predictors of conflict outcome: Solving the paradox in a South American cichlid fish. Animal Behaviour, 62, 623-634.

MAYNARD SMITH, J. (1982). Evolution and the theory of games. Cambridge: Cambridge University Press.

McGregor, P. K., \& Dabelsteen, T. (1996). Communication networks. In D. E. Kroodsma \& E. H. Miller (Eds.), Ecology and evolution of acoustic communication in birds (pp. 409-425). Ithaca, NY: Cornell University Press.

McGregor, P. K., \& PeAKe, T. M. (2000). Communication networks: Social environments for receiving and signalling behavior. Acta Ethologica, 2, 71-81.

McGregor, P. K., PeAke, T. M., \& LAmpe, H. M. (2001). Fighting fish Betta splendens extract relative information from apparent interactions: What happens when what you see is not what you get. Animal Behaviour, 62, 1059-1065.

NAguib, M., Fichtel, C., \& TodT, D. (1999). Nightingales respond more strongly to vocal leaders of simulated dyadic interactions. Proceedings of the Royal Society of London: Series B, 266, 537-542.

Neat, F. C., Huntingford, F. A., \& Beveridge, M. M. C. (1998). Fighting and assessment in male cichlid fish: The effects of asymmetries in gonadal state and body size. Animal Behaviour, 55, 883-891.

Neat, F. C., Taylor, A. C., \& Huntingford, F. A. (1998). Proximate costs of fighting in male cichlid fish: The role of injuries and energy metabolism. Animal Behaviour, 55, 875-882.

Oliveira, R. F., Lopes, M., Carneiro, L. A., \& Canario, A. V. M. (2001). Watching fights raises fish hormone levels. Nature, 409, 475.

Oliveira, R. F., MCGRegor, P. K., \& LAtrufFe, C. (1998). Know thine enemy: Fighting fish gather information from observing conspecific interactions. Proceedings of the Royal Society of London: Series B, 265, 1045-1049.

Oliveira, R. F., Rosenthal, G. G., Schlupp, I., McGregor, P. K., Cuthill, I., Endler, J. A., Fleishman, L. J., Zeil, J., Barata, E., Burford, F., Gon alves, D., HAley, M., JAKOBSSON, S., JenNions, M. D., Körner, K. E., Lindström, L., Peake, T., Pilastro, A., Pope, D. S., Roberts, S., Rowe, C., SMith, J., \& WAAS, J. R. (2000). Considerations on the use of video playbacks as visual stimuli: The Lisbon workshop consensus. Acta Ethologica, 3, 61-65.

PEAKE, T. M. (in press). Eavesdropping in communication networks. In P. K. McGregor (Ed.), Animal communication networks. Cambridge: Cambridge University Press.

Peake, T. M., Terry, A. M. R., McGregor, P. K., \& Dabelsteen, T. (2001). Male great tits eavesdrop on simulated male-to-male vocal interactions. Proceedings of the Royal Society of London: Series B, 268, 1183-1187.

Peake, T. M., Terry, A. M. R., McGregor, P. K., \& Dabelsteen, T. (2002). Do great tits assess rivals by combining direct experience with information gathered by eavesdropping? Proceeding sof the Royal Society of London: Series B, 269, 1925-1929.

Pepperberg, I. M. (in press). Cognitive aspects of networks and avian capacities. In P. K. McGregor (Ed.), Animal communication networks. Cambridge: Cambridge University Press.

RASA, O. A. E. (1969). Territoriality and the establishment of dominance by means of visual cues in Pomacentrus jenkinsi (Pisces: Pomacentridae). Zeitschrift für Tierpsychologie, 26, 825-845.

RiBOWSKI, A., \& FRANCK, D. (1993). Demonstration of strength and concealment of weakness in escalating fights of male swordtails (Xiphophorus helleri). Ethology, 93, 265-274.

SCHLUPP, I., \& RYAN, M. J. (1997). Male sailfin mollies (Poecilia latipinna) copy the mate choice of other males. Behavioral Ecology, 8 , 104-107.

Simpson, M. J. A. (1968). The display of the Siamese fighting fish Betta splendens. Animal Behaviour Monographs, 1, 1-73.

TURNER, G. F. (1994). The fighting tactics of male mouthbrooding cichlids: The effects of size and residency. Animal Behaviour, 47, 655-662.

WAAS, J. R., \& COLGAN, P. W. (1992). Chemical cues associated with visually elaborate aggressive displays of 3-spine sticklebacks. Journal of Chemical Ecology, 18, 2277-2284. 
Westby, G. W. M. (1975). Further analysis of the individual discharge characteristics predicting social dominance in the electric fish Gymnotus carapo. Animal Behaviour, 23, 249-260.

WestBy, G. W. M. (1988). The ecology, discharger diversity and predatory behaviour of gymnotiforme electric fish in the coastal streams of French Guiana. Behavioural Ecology \& Sociobiology, 22, 341-354

Westneat, D. F., Walters, A., McCarthy, T. M., Нatch, M. I., \& HeIN, W. K. (2000). Alternative mechanisms of nonindependentmate choice. Animal Behaviour, 59, 467-476.

White, D. J., \& GALEF, B. G., JR. (2000a). "Culture" in quail: Social influences on mate choice of female Coturnix japonica. Animal Behav iour, 59, 975-979.

White, D. J., \& Galef, B. G., JR. (2000b). Differences between the sexes in direction and duration of response to seeing a potential sex partner mate with another. Animal Behaviour, 59, 1235-1240.

WISENDEN, B. D., \& STACEY, N.E. (in press). Fish semiochemicals and the evolution of communication networks. In P. K. McGregor (Ed.), Animal communication networks. Cambridge: Cambridge University Press.

Witte, K., \& Massmann, R. (2003). Female sailfin mollies, Poecilia latipinna, remember males and copy the choice of others after 1 day. Animal Behaviour, 64, 1151-1159.

Witte, K., \& Nolteme IER, B. (2002). The role of information in matechoice copying in female sailfin mollies (Poecilia latipinna). Behavioral Ecology \& Sociobiology, 52, 194-202.

Witte, K., \& Ueding, K. (2003). Sailfin molly females (Poecilia latipinna) copy the rejection of a male. Behavioral Ecology, 14, 389-395. 